\title{
Dimerization specificity of myogenic helix-loop-helix DNA-binding factors directed by nonconserved hydrophilic residues
}

\author{
Masaki Shirakata, Fred K. Friedman, ${ }^{1}$ Qin Wei, and Bruce M. Paterson \\ Laboratory of Biochemistry, ${ }^{1}$ Laboratory of Molecular Carcinogenesis, National Cancer Institute, National Institutes \\ of Health, Bethesda, Maryland 20892 USA
}

\begin{abstract}
The myogenic regulatory factor MyoD dimerizes with other positive and negative regulatory factors through a conserved region called the helix-loop-helix (HLH) domain. Using a non-DNA-binding MyoD mutant with a normal HLH domain as a dimerization competitor in gel mobility shift assays in conjunction with various MyoD HLH mutants, nonhydrophobic amino acids were identified in the HLH domain that contribute to dimerization specificity with E12. The assay detected subtle differences in dimerization activity among the mutant MyoD proteins that correlated with their ability to activate transcription in vivo, but this correlation was not apparent in the absence of competitor. The identification of such nonhydrophobic residues enabled us to predict the differences in dimerization affinity among the four vertebrate myogenic factors with E12. The experiments confirmed the prediction. Furthermore, a high-affinity homodimerizing analog of MyoD was designed by a single substitution at one of these residue positions. These experimental results were strengthened when they were analyzed in terms of the crystal structure for the Max bHLHZip domain homodimer. This analysis has allowed us to identify those residues that form charged residue pairs between the two HLH domains of MyOD and E12 and determine the dimerization specificity of the bHLH proteins.
\end{abstract}

[Key Words: Transcriptional factor; dominant negative mutant; muscle development; gene regulation; site-directed mutagenesis]

Received April 30, 1993; revised version accepted September 14, 1993.

The discovery of numerous transcriptional regulatory proteins that share a similar dimerization and DNAbinding motif and that bind to a common DNA target sequence has revealed the complexity of gene regulation involving these factors (Karin 1990). Although the sequence specificity of DNA binding is the principal determinant of the genes to be regulated, the specificity of dimerization appears to govern the mode of gene regulation (Jones 1990; Karin 1990).

$\mathrm{MyoD}$ is a myogenic regulatory factor that can induce fibroblasts to differentiate into muscle cells (Davis et al. 1987; Tapscott et al. 1988) and is involved in the transcriptional activation of numerous muscle-specific genes (Lassar et al. 1989). The dimerization and DNA-binding domain of MyoD has a basic helix-loop-helix (bHLH) motif that is found in a variety of sequence-specific DNA-binding proteins (Jones 1990). The proposed structure for the $\mathrm{bHLH}$ motif postulates that the basic or DNA-binding domain is joined to two putative amphipathic helices separated by a variable length loop (Murre et al. 1989). The hydrophobic interface of each amphipathic helix is thought to mediate dimerization (Davis et al. 1990; Voronova and Baltimore 1990). The structure of the bHLH domain is unknown, although various fourhelix bundle models have been proposed (Anthony et al. 1992; Halazonetis and Kandil 1992; Starovansnik et al. 1992). Recently, the crystal structure of a Max homodimer-DNA complex was reported (Ferré-D'Amaré et al. 1993). Max is a member of the bHLHZip family of proteins and contains a DNA-binding and dimerization domain consisting of the bHLH motif and the leucine zipper motif (Blackwood and Eisenman 1991; Prendergast et al. 1991). The Max dimer structure largely confirmed the HLH domain models predicting that helix 1 and helix 2 form a parallel four-helix bundle with the loops to the outside (Anthony et al. 1992; Halazonetis and Kandil 1992).

MyoD forms either a homodimer or a heterodimer with the ubiquitous bHLH protein E12, as well as other E12-related proteins (Murre et al. 1989; Henthorn et al. 1990; Hu et al. 1992), and binds to a preferred DNA motif with the consensus sequence CANNTG, also known as an E-box (Blackwell and Weintraub 1990). Heterodimerization with E12 has been shown to occur in vivo and is thought to be essential for the DNA-binding and transcriptional activation by MyoD protein (Davis et al. 1990). 
To date, muscle cells have been shown to express four myogenic bHLH factors (Davis et al. 1987; Braun et al. 1989; Edmondson and Olson 1989; Rhodes and Konieczny 1989; Wright et al. 1989), at least four ubiquitous E12-related bHLH proteins (Murre et al. 1989; Henthorn et al. 1990; Hu et al. 1992), and three negative regulatory HLH proteins, the Id proteins (Benezra et al. 1990; Christy et al. 1991; Sun et al. 1991; Biggs et al. 1992). In general, all of these HLH proteins can form either homodimers or heterodimers with each other, but the dimerization affinity differs among dimers according to the dimerization specificity of each HLH protein. For example, MyoD preferably forms a heterodimer with E12 rather than a homodimer (Murre et al. 1989; Sun and Baltimore 1991). The implication of these findings is that dimerization of the bHLH proteins may be highly competitive in the cell and therefore suggests that dimerization specificity plays a major role in gene regulation.

To understand this dimerization specificity, we have initiated experiments to determine the amino acid residues that stabilize or destabilize the dimer of the HLH domain. Several site-directed mutation studies have been done for the HLH proteins (Davis et al. 1990; Voronova and Baltimore 1990; Winter et al. 1992). These studies indicated the importance of the conserved hydrophobic residues in both helix 1 and helix 2 for the dimer formation, but nothing was determined with regard to dimerization specificity. Thus, little is known about the nonconserved residues that may also contribute to the dimerization specificity of the bHLH proteins. Clarification of this point would not only help to explain the molecular basis of dimerization specificity for the bHLH proteins but would also be a step toward defining preliminary rules govering the dimerization specificity. Such rules might enable one to predict particular or preferred dimerization partners and might also allow one to design mutant HLH proteins that would provide powerful set of reagents to investigate the function of the original proteins in vivo (Amati et al. 1993).

In this study we have addressed the question of dimerization specificity in the bHLH proteins; for example, the dimerization of $\mathrm{MyoD}$ and $\mathrm{E} 12$ was analyzed in vitro and in vivo. Mutant $\mathrm{MyoD}$ proteins containing various amino acid substitutions in the HLH domain were used to identify the residues important for dimerization specificity. Previous studies have indicated that Drosophila $\mathrm{MyoD}$ forms the heterodimer inefficiently with vertebrate E12, in spite of the identical hydrophobic residues in the HLH domains of Drosophila and vertebrate MyoD (Michelson et al. 1990; Paterson et al. 1991). Thus, we used the Drosophila MyoD HLH sequence as the starting point for our mutant analyses. To analyze the subtle mutational effects on dimerization, the gel mobility shift assay was used together with a dominant negative mutant of $\mathrm{MyoD}$ as a specific competitor protein in the dimerization reaction. The experiments identified important residues for specific dimerization at three nonhydrophobic positions in helix 1 and helix 2 . These results were used to predict the differences in the dimer- ization affinity between E12 and the four myogenic $\mathrm{HLH}$ proteins, based on the primary sequences in the HLH region. The prediction was confirmed by experimentation. We have interpreted the results of our mutational experiments further, using the coordinates of the Max bHLHZip homodimer-DNA crystal structure. Finally, we suggest the potential residue pairs in the HLH domain that may determine the dimerization specificity.

\section{Results \\ Use of non-DNA-binding MyoD mutant as a specific competitor protein in a gel mobility-shift assay}

To study the specific dimerization of MyoD and E12, we prepared the full-length His-tagged proteins expressed in Escherichia coli (Fig. 1A). Analytical gel filtration chromatography on a Superose 12 column (Pharmacia-LKB) suggested that both His-tagged MyoD and E12 were predominantly monomers or dimers in solution in the absence of DNA (data not shown). In gel mobility shift assays using an E-box consensus oligonucleotide, the MyoD homodimer bound with lower affinity compared with the MyoD-E12 heterodimer, and binding by E12 alone was barely detectable (Fig. 1B). Similar results have been reported for the in vitro-translated proteins (Murre et al. 1989).

The gel mobility shift assay was used throughout our experiments to quantitate the extent of dimerization because several mutational studies have established that MyoD and E12 must dimerize through the HLH domain to bind DNA (Davis et al. 1990). In the standard assay,

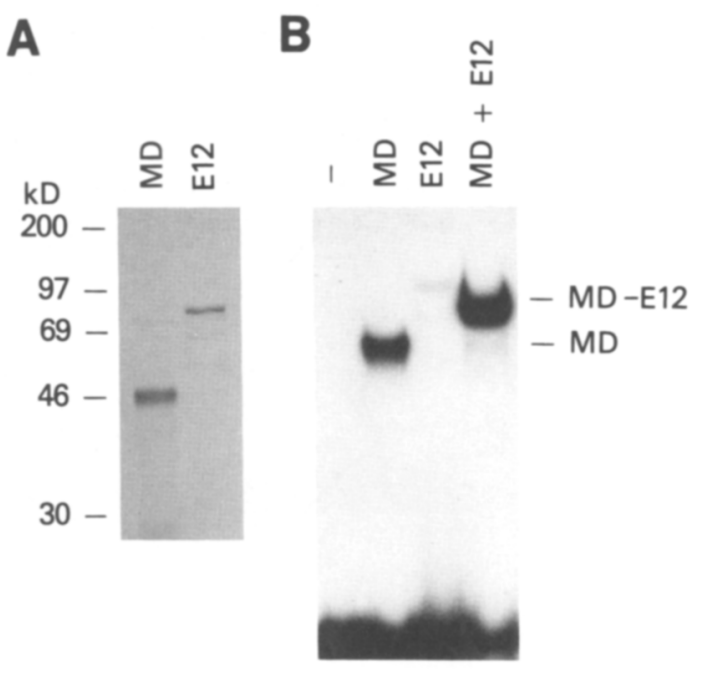

Figure 1. His-tagged MyoD and E12 proteins. (A) SDS-polyacrylamide gel electrophoresis analysis of His-tagged MyoD (MD) and E12. (B) Gel mobility shift analysis. His-tagged MyoD (20 ng) or E12 (60 ng), or the mixture of both (MD + E12), was reacted with the E-box DNA probe. The positions of the MyoDE12 (MD-E12) heterodimer and the MyoD homodimer (MD) are indicated (right). The faint band seen with E12 alone (E12) is the E12 oligomer. 
the purified MyoD and E12 proteins were mixed with the probe DNA and then subjected to native gel electrophoresis (see Material and methods). In this reaction, the protein dimerization occurs without competition. Preliminary experiments with the purified proteins indicated that the gel mobility shift assay did not detect small differences in the affinity of E12 for different MyoD HLH mutants. To detect subtle differences in dimerization affinity, we measured MyoD-E12 heterodimerization in the presence of a specific bHLH competitor protein, a dominant negative mutant of MyoD. We reasoned that a dominant negative mutant lacking DNA-binding ability but having the HLH domain intact would dimerize with E12 and compete with the various MyoD HLH mutants in the heterodimerization reaction similar to the competition among the bHLH proteins that may occur in vivo. The differences in dimerization affinity of wild-type MyoD and the test MyoD would be revealed by the degree of competition between the dominant negative mutant $\mathrm{MyoD}$ and a test $\mathrm{MyoD}$ in a dimerization reaction with E12. This "selection effect" has been applied very effectively for the analysis of protein-protein interactions between calmodulin and calcineurin (Chen and Brew 1989). We constructed a cDNA encoding the mutant protein $\mathrm{M} \triangle \mathrm{B} 2$ as a full-length MyoD protein containing a triple substitution in the basic region: wild-type $\mathrm{Arg}^{101}-\mathrm{Arg}^{102}-\mathrm{Lys}^{103}$ to $\mathrm{Ala}^{101}$ $\mathrm{Ala}^{102}-\mathrm{Ala}^{103}$. These substitutions in $\mathrm{M} \Delta \mathrm{B} 2$ remove the second basic amino acid cluster that has been shown to be essential for DNA binding, but the HLH domain remains intact (Davis et al. 1990). As expected, $\mathrm{M} \Delta \mathrm{B} 2$ did not bind to the E-box DNA (Fig. 2A) and was able to reduce the DNA-binding of the wild-type MyoD-E12 heterodimer in a concentration-dependent manner (Fig. $2 \mathrm{~B}, \mathrm{C}$ ). Because $\mathrm{M} \Delta \mathrm{B} 2$ does not bind DNA, this result indicates that $\mathrm{M} \triangle \mathrm{B} 2$ competes effectively with $\mathrm{MyoD}$ in the heterodimerization reaction with E12.

To establish the specificity of the HLH interactions between the competitor $\mathrm{M} \Delta \mathrm{B} 2$ and E12, we tested another variant. M $\triangle \mathrm{B} 2 \mathrm{AF}$ has additional substitutions in the MyoD HLH domain that change $\mathrm{Phe}^{120}$ in helix 1 to $\mathrm{Ala}$ and $\mathrm{Ala}^{144}$ in helix 2 to Phe. These substitutions eliminate the dimerization of MyoD altogether (see Fig. 5, below; F120A/A144F). As shown in Figure 2, B and C, $M \triangle B 2 A F$ does not bind DNA but, unlike $M \Delta B 2$, $M \triangle B 2 A F$, does not compete with MyoD in the binding assay. This result indicates that the dimerization competition by $M \Delta B 2$ is specific and dependent on the HLH domain structure.

\section{Dimerization and DNA binding of chimeric MyoD proteins with $\mathrm{E} 12$}

We reasoned that if the HLH motif contributes to the dimerization specificity, then the nonhydrophobic residues should play an important role in this process, because the hydrophobic residues in the HLH domain of the bHLH proteins are highly conserved (Murre et al. 1989). Previously, we and others had isolated the Drosophila homolog to MyoD, called Dmyd or nautilus (Michelson et al. 1990; Paterson et al. 1991), which, unlike MyoD, does not efficiently convert C3H10T1/2 mouse fibroblasts to muscle (Paterson et al. 1992). Dmyd and MyoD share an extensive amino acid sequence identity in the bHLH domain, which alone is sufficient for myoblast conversion, but little similarity outside this region (Tapscott et al. 1988). Dmyd has six amino acid changes and one insertion in the cysteine-basic region and five changes in the HLH domain when compared with the
A

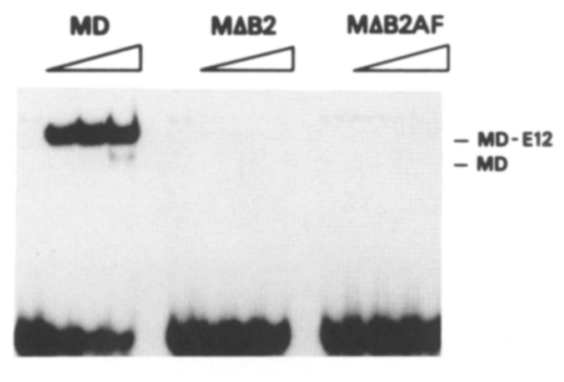

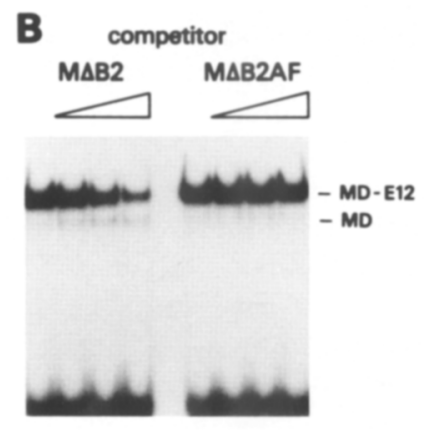

C

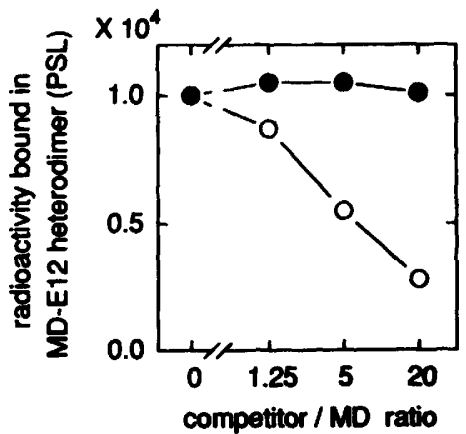

Figure 2. Characterization of the dominant negative mutant of $M y o D, M \Delta B 2$. $(A)$ Gel mobility-shift analysis of dimerization and DNA binding by MyoD (MD), M $\Delta \mathrm{B} 2$, and $\mathrm{M} \Delta \mathrm{B} 2 \mathrm{AF}$ with $\mathrm{E} 12$. Varying amounts of MyoD protein $(0,3.1,12.5,50 \mathrm{ng})$ were reacted with E12 protein $(60 \mathrm{ng}$ ) and the E-box DNA probe. The positions of the MyoD-E12 (MD-E12) heterodimer and the MyoD homodimer (MD) are indicated $(r i g h t) .(B)$ Competitive inhibition of the heterodimerization and DNA binding of MyoD and E12 by M $\Delta \mathrm{B} 2$ protein. M $\Delta \mathrm{B} 2$ or $\mathrm{M} \triangle \mathrm{B} 2 \mathrm{AF}$ proteins $(0,25,100,400 \mathrm{ng})$ were coincubated with wild-type MyoD (20 ng), E12 (60 ng), and the E-box DNA probe. The molar ratio of the competitor $(\mathrm{M} \Delta \mathrm{B} 2, \mathrm{M} \Delta \mathrm{B} 2 \mathrm{AF})$ to $\mathrm{MyoD}$ was $0,1.25,5$, and 20. $(C)$ Graphic representation of the results described in $B$. The radioactivity contained in the MyoD-E12 dimer E-box DNA complex formed in the presence of $M \Delta B 2(O)$ or $M \Delta B 2 A F(O)$ was measured in the Bio-Image Analyzer BAS2000 (FUJI). Total radioactivity in each lane was $2.3 \times 10^{4}$ photostimulated luminescence units (PSL). 
MyoD sequence (Fig. 3A). All of the changes in the bHLH domains involve nonhydrophobic residues, whereas the hydrophobic residues are completely conserved. We constructed various chimeric MyoD cDNAs by replacing the MyoD Cys--bHLH region with the corresponding region of Dmyd, either in part or entirely. The various chimeric proteins were then tested for their ability to dimerize with E12 and bind to the E-box target sequence in the absence or presence of the competitor protein $\mathrm{M} \triangle \mathrm{B} 2$. As mentioned previously, all of the chimeric MyoD proteins dimerized with E12 and bound to DNA almost as well as wild-type $\mathrm{MyoD}$ in the absence of $\mathrm{M} \Delta \mathrm{B} 2$ (>75\% MD) (Fig. 3B).

The dimerization and DNA-binding of the same MyoD mutants were then analyzed in the presence of the specific competitor $M \Delta B 2$ (Fig. $3 \mathrm{C}$ ). As expected, the competition experiments carried out with the $\mathrm{M} \Delta \mathrm{B} 2$ protein in the reaction revealed differences in the dimerization affinity that were not evident when the reaction was measured directly in the absence of competitor. In the presence of an eightfold excess of competitor, relative DNA-binding levels of E12 with the MdBHLH and

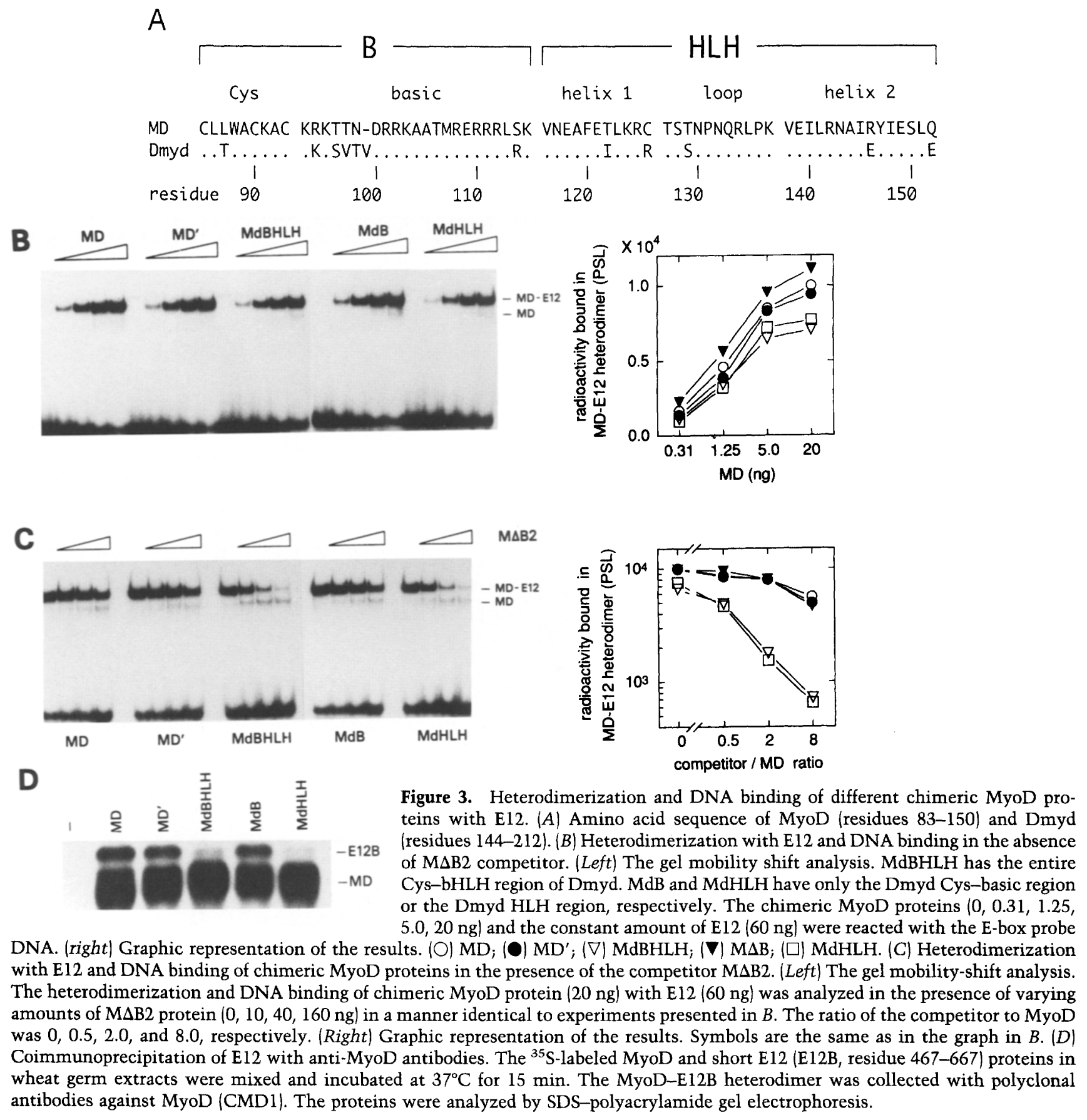


MdHLH MyoD mutants containing the Drosophila HLH domain were reduced to $10 \%$ of the level seen with wildtype MyoD (Fig. 3C, right). When we compared the amount of competitor required to inhibit the DNA binding by $50 \%, 16$-fold less competitor was needed with MdBHLH and MdHLH than with wild-type MyoD. Clearly, the Dmyd HLH amino acid substitutions affected dimerization with E12 and DNA binding to the greatest extent when they were introduced at the nonhydrophobic positions in the MyoD HLH domain.

We also examined the dimerization of the MyoD variants and E12 in the absence of DNA using wheat germ extracts to synthesize the ${ }^{35}$ S-labeled proteins. Coimmunoprecipitation experiments with antibody to MyoD confirmed the reduced dimerization affinity of E12 with the chimeric MyoD proteins containing the Dmyd HLH domain (Fig. 3D). In the gel mobility shift assay in the absence of the competitor protein (Fig. 3B), both MdBHLH and MdHLH bound DNA better than expected from the immunoprecipitation results (Fig. 3D), suggesting that DNA binding may facilitate and/or stabilize dimerization under certain circumstances.
Nonhydrophobic residues in MyoD HLH domain that facilitate specific dimerization and DNA binding with E12

The Drosophila-like chimeric MyoD, MdHLH, has five amino acid substitutions in the HLH domain compared with the original MyoD protein (Fig. 3A). We examined the role of each of these amino acid residues in the dimerization using single or multiple substitutions (Fig. 4A). The chimeric MyoD proteins were analyzed in the gel shift assay (Fig. 4B). In the presence of an eightfold excess of $\mathrm{M} \triangle \mathrm{B} 2$ competitor (right lane in each series), C126R and R146E formed only $30 \%$ of the heterodimer complex when compared with wild-type MyoD. The reaction with mutant Q152E was weakly but reproducibly inhibited by $\mathrm{M} \triangle \mathrm{B} 2$ as well. The mutant M-IRSEE, containing all five substitutions, showed the lowest heterodimer formation. This suggested that the effects of the substitutions were additive. At this point, we have identified three residues in the MyoD HLH domain, Cys ${ }^{126}$ in helix 1, and $\operatorname{Arg}^{146}$ and $\operatorname{Gln}^{152}$ in helix 2, that are important for the specific heterodimerization of $\mathrm{MyoD}$

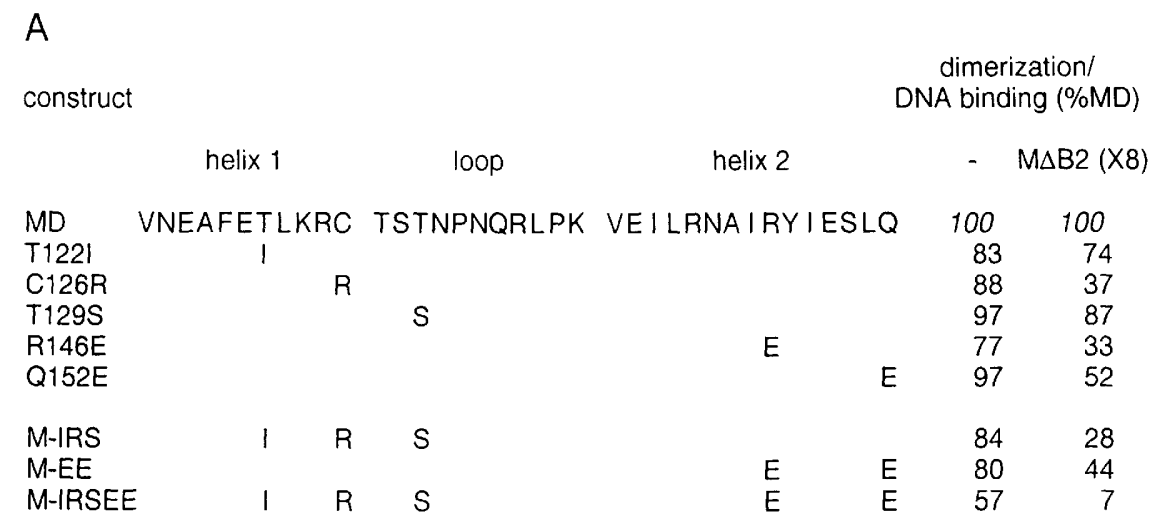

B

Figure 4. Mutation of the nonhydrophobic residues in the MyoD HLH region. (A) The sequences of the wild-type and mutant MyoD HLH regions. Only amino acid changes that differ from wild-type are shown for the mutants. The relative heterodimerization of the mutants was calculated from the gel mobility shift assay as described in $B$. The radioactivity bound with wild-type MyoD was normalized to $100 \%$ separately for each experiment, either in the absence $(-)$ or with an eightfold excess of the competitor $\mathrm{M} \Delta \mathrm{B} 2[\mathrm{M} \Delta \mathrm{B} 2(\times 8)] .(B)$ Gel mobility shift analysis of the mutant MyoD proteins. The heterodimerization of the mutant MyoD (20 ng) and E12 (60 ng) was analyzed in the presence of varying amounts of $M \Delta \mathrm{B} 2$ protein $(0,10,40,160 \mathrm{ng})$ as described in Fig. $2 \mathrm{C}$. The ratio of the competitor $\mathrm{M} \triangle \mathrm{B} 2$ to $\mathrm{MyoD}$ was $0,0.5,2.0$, and 8.0 , respectively.

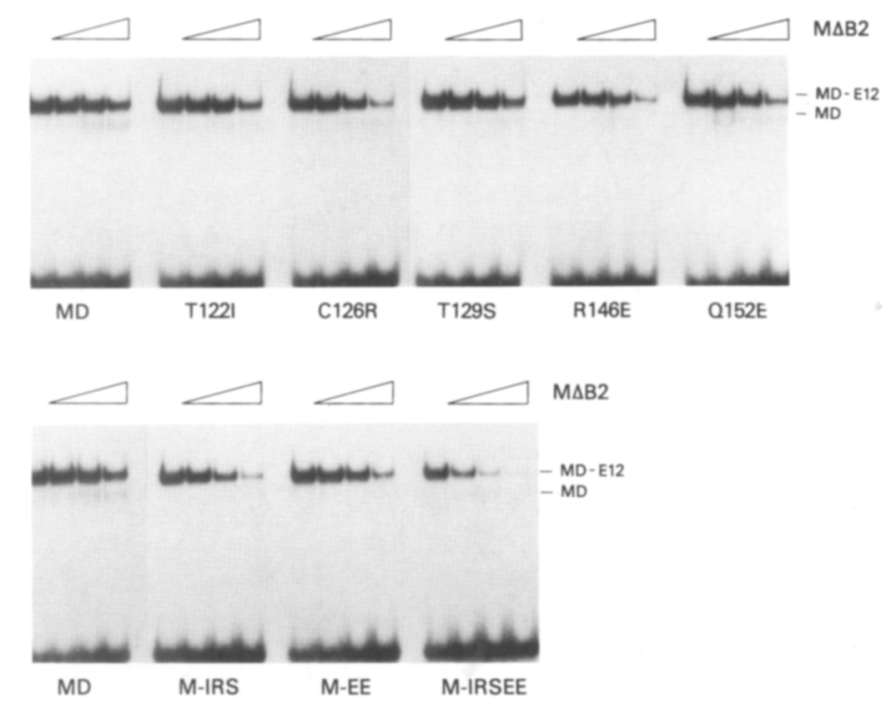


and E12. These amino acid substitutions (Figs. 3 and 4 ) change the electrostatic charge at residue 126 (Cys $\rightarrow$ $\mathrm{Arg}$ ), residue 146 (Arg $\rightarrow \mathrm{Glu}$ ), and residue 152 (Gln $\rightarrow \mathrm{Glu}$ ) and apparently disrupt the interactions between MyoD and E12. This is examined in further detail below.

\section{Conserved phenylalanine in MyoD helix 1 mediates} the specific dimerization with E12

We then examined the roles of conserved hydrophobic residues in the HLH domain. bZIP domains contain heptad leucine repeats in the amphipathic helices that facilitate the hydrophobic interaction at the dimerization interface (Landschulz et al. 1989; O'Shea et al. 1992a; Ellenberger et al. 1993). The HLH domain has no such structural feature (Murre et al. 1989). The bHLH motif has a phenylalanine in the middle of helix 1 (Figs. 3A and $5 \mathrm{~A} ; \mathrm{Phe}^{120}$ ) that is conserved among most of the bHLH proteins identified so far, as well as in a group of bHLHZIP proteins that includes Myc and Max (Blackwood and Eisenman 1991; Prendergast et al. 1991). To understand the role of this phenylalanine residue in dimerization, we tested a series of amino acid substitutions in the gel shift assay (Fig. 5). With $M \Delta B 2$ competitor present in the binding assay, MyoD Phe ${ }^{120}$ was crucial for the DNA binding of the MyoD-E12 heterodimer (Fig. 5B). The substitution of alanine for phenylalanine (F120A) eliminated DNA binding altogether. Because the phenylalanine side chain is hydrophobic in nature, we also tested the substitution of valine, isoleucine, and leucine at this position (F120V, F120I, F120L). The trend in binding activity suggested that the larger the hydrophobic side chain is the higher the binding affinity $(\mathrm{Ala}<\mathrm{Val}<$ Ile $<$ Leu). However, none of these substitutions could bind DNA effectively in the presence of $M \Delta B 2$. Tyrosine, which is similar to phenylalanine in structure but less hydrophobic, could substitute more efficiently for phenylalanine (F120Y). These results indicated that phenylalanine, but not other hydrophobic amino acids, had an important role at position 120 in MyoD helix 1 in mediating the heterodimerization of MyoD and E12. This specific requirement is consistent with the idea that the stacking of the side chains and/or the aromatic nature of phenylalanine is important for the interaction between the two bHLH proteins.

Because Phe ${ }^{120}$ is unique in the HLH domain and appears important for dimer formation, it may define a key position in the putative hydrophobic interface. To test this further, we asked whether Phe ${ }^{120}$ could be exchanged in position with other hydrophobic residues in the $\mathrm{HLH}$ region. Based on a parallel four-helix bundle model for the bHLH dimer (Anthony et al. 1992; Halazonetis and Kandil 1992), we chose to alter Ile ${ }^{145}$ and $\mathrm{Ala}^{145}$ in helix 2. As shown in Figure 5, Phe ${ }^{120}$ could not exchange position with either $\mathrm{Ile}^{145}$ or $\mathrm{Ala}^{144}$ (F120 I/I145F, F120A/A144F), suggesting that the position and interaction of the phenylalanine residue plays a crucial role in the putative hydrophobic dimer interface of the bHLH proteins. This is discussed further with regard to the Max bHLHZip homodimer-DNA crystal structure (see below).

\section{Transcriptional activation by MyoD HLH mutants in cultured cells}

To demonstrate the significance of the differences in dimerization affinity revealed by the specific competitor, we tested the transcriptional activation by all of the MyoD mutants in cotransfection assays. The various HLH proteins in the cell could now act similarly to $\mathrm{M} \triangle \mathrm{B} 2$ in our in vitro assay to reveal differences in the dimerization affinities of the various MyoD HLH mutations. Previous studies have established that ectopically expressed MyoD heterodimerizes with endogenous E12 (Lassar et al. 1991) and activates transcription from target sequences, such as the E-box in the MCK enhancer joined to the chloramphenicol acetyltransferase (CAT) reporter gene (Lassar et al. 1989; Weintraub et al. 1991). Although this is an indirect method, the dimerization and DNA binding of MyoD in vivo can be analyzed by measuring CAT activity expressed in cotransfected cells. We observed significant differences in CAT expression among the MyoD mutants (Table 1; MD transfection). Furthermore, there was a reasonable correlation between the relative amount of CAT activity and the DNA binding of the MyoD mutants measured in the presence of the competitor $\mathrm{M} \Delta \mathrm{B} 2$.

When we cotransfected an E12 expression plasmid with the MyoD mutant constructs and the CAT reporter gene into $\mathrm{C} 3 \mathrm{H} 10 \mathrm{~T} 1 / 2$ cells, we observed fewer differences in CAT expression than when reactions depended on endogenous E12 (Table 1, MD-E12 cotransfection). We interpret this result to imply that increased expression of both $\mathrm{E} 12$ and $\mathrm{MyoD}$ overcomes the competition from various cellular bHLH proteins through the effects of mass action. Activation levels now reflect the binding that we observe for the MyoD-E12 heterodimer in vitro in the absence of competitor.

\section{Differences among four myogenic bHLH factors in the heterodimerization with E12}

As stated earlier, we have identified at least three nonhydrophobic residues, $\mathrm{Cys}^{126}, \operatorname{Arg}^{146}, \mathrm{Gln}^{152}$, that are important for the specific heterodimerization of $\mathrm{MyoD}$ with E12. When comparing the amino acid residues of the four myogenic factors with the positions $\mathrm{Cys}^{126}$, $\operatorname{Arg}^{146}$, and $\mathrm{Gln}^{152}$ in MyoD (Fig. 6A), we found that myogenin has Ser at $\mathrm{Cys}^{126}$, and Gln at $\operatorname{Arg}^{146}$, and MRF4 has Arg at Cys ${ }^{126}$, and Ser at Arg ${ }^{146}$. All of these differences would alter the electrostatic charge at these positions. Myf5 is identical to MyoD at these three positions. We speculated that MyoD/Myf5, myogenin, and MRF4 would have different dimerization affinities with E12 and, by inference, other potential dimer partner proteins in the cell.

To test this prediction by experimentation, we compared the DNA binding and dimerization of the four myogenic $\mathrm{HLH}$ proteins in the presence of competitor 
A

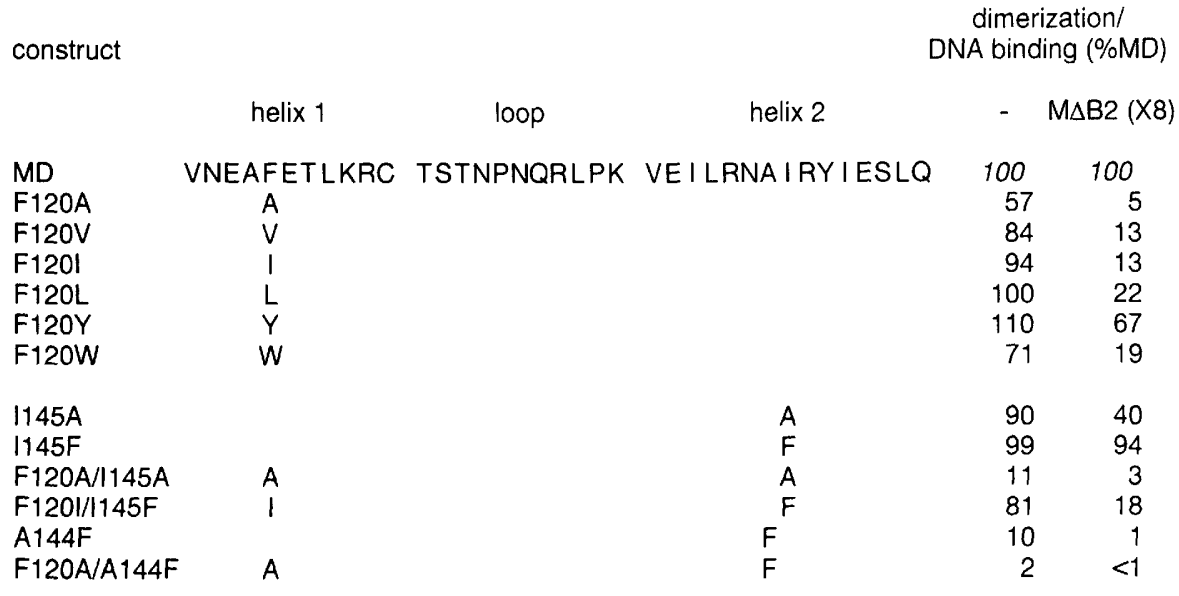

B
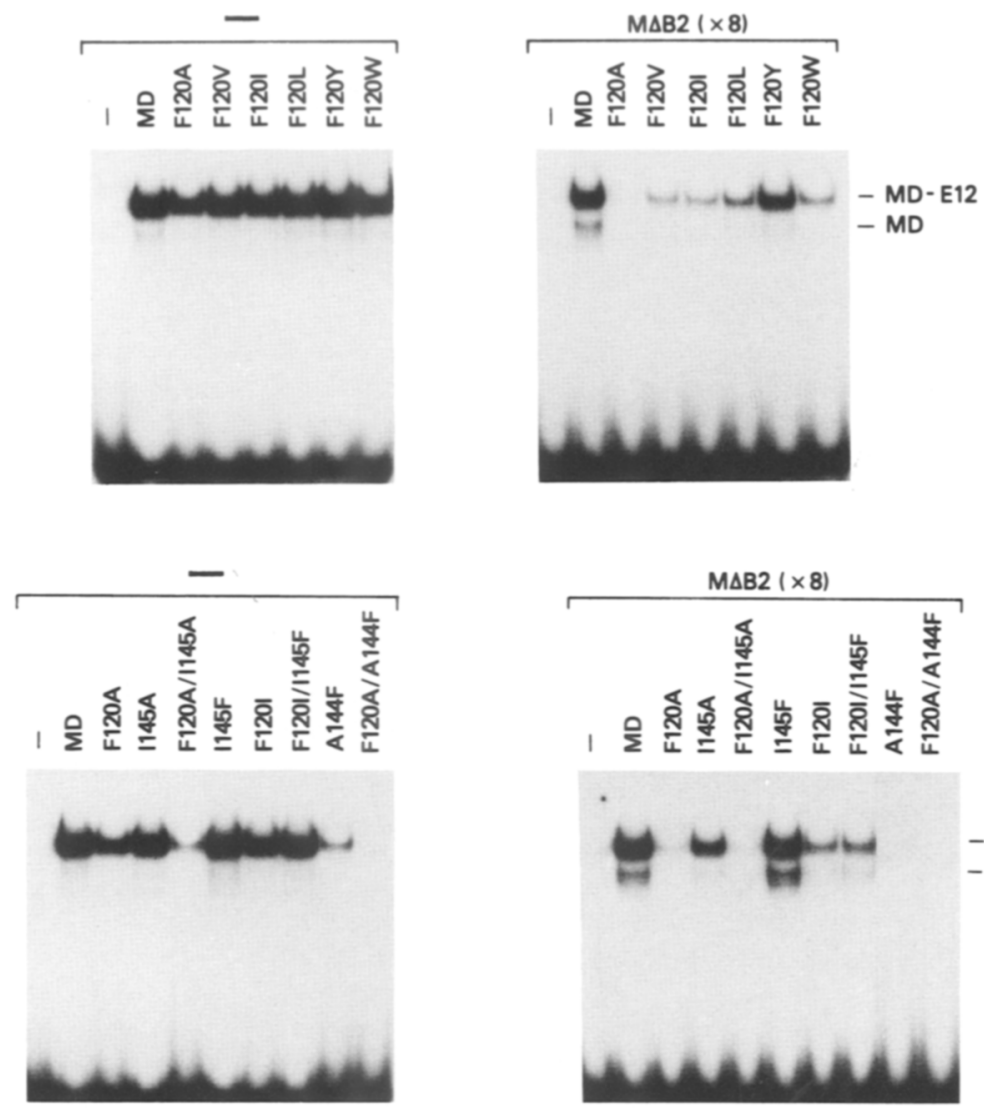

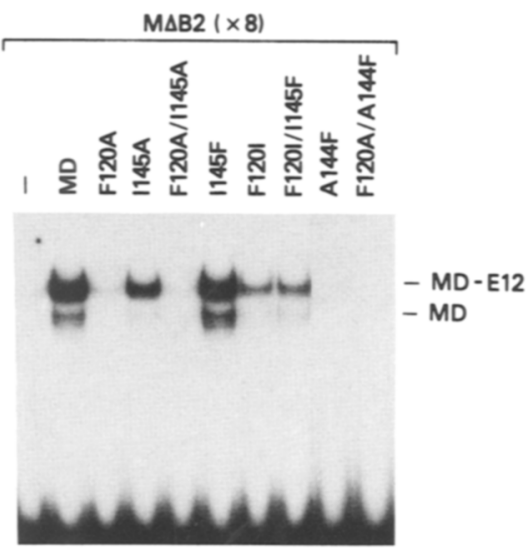

Figure 5. Mutations of the conserved hydrophobic residues in the MyoD HLH region. $(A)$ The sequence of the MyoD HLH region and the various mutants. Only the amino acid changes that differ from wild-type are shown for the mutants. The relative heterodimerization of the mutants was calculated from the gel mobility shift assay. (B) Gel mobility shift analysis of the mutant MyoD proteins. The heterodimerization of the mutant MyoD 120 $\mathrm{ng}$ ) and E12 (60 ng) proteins was analyzed in the absence $(-)$ or presence of an eightfold excess of $M \Delta B 2$ protein (160 ng) [M $\Delta B 2(\times 8)]$ as described in Fig. 2C. protein (Fig. 6B). MyoD and Myf5 bound DNA with the highest affinity, and myogenin showed a lower affinity than either MyoD or Myf5. MRF4 had the lowest affinity for E12 among these four factors. Because myogenin has a single-residue change and MRF4 has two changes at the positions identified for dimerization specificity with MyoD, these results were consistent with the predictions based on MyoD-E12 interactions. We also tested DNA binding of the various homodimers (Fig. 6C). Sim- ilar to the heterodimerization results, $\mathrm{MyoD}$ and Myf5 had higher affinities as homodimers when compared with myogenin, and MRF4 showed the lowest affinity binding of all the factors. These results support our predictions concerning the similarity between $M y o D$ and Myf5 and the differences between MyoD/Myf5, myogenin, and MRF4 in dimerization specificity. Moreover, when taken together, the results of these and the MyoD mutation experiments suggest that dimerization speci- 
Table 1. Transcriptional activation of MyoD mutants

\begin{tabular}{|c|c|c|c|}
\hline \multirow[b]{2}{*}{ Construct } & \multirow{2}{*}{$\begin{array}{l}\text { Relative } \\
\text { dimerization/ } \\
\text { DNA binding } \\
\text { (×8 M } \Delta \mathrm{B} 2 \text { ) }\end{array}$} & \multicolumn{2}{|c|}{ Relative CAT activity $(\% \mathrm{MD})$} \\
\hline & & $\begin{array}{l}\text { MD } \\
\text { transfection }\end{array}$ & $\begin{array}{l}\text { MD-E12 } \\
\text { cotransfection }\end{array}$ \\
\hline MD & 100 & 100 & 100 \\
\hline $\mathrm{MD}^{\prime}$ & 88 & 97 & 97 \\
\hline MdBHLH & 13 & 21 & 40 \\
\hline $\mathrm{MdB}$ & 82 & 124 & 127 \\
\hline MdHLH & 12 & 10 & 24 \\
\hline $\mathrm{MD}$ & 100 & 100 & 100 \\
\hline T122I & 74 & 93 & 95 \\
\hline C126R & 37 & 86 & 80 \\
\hline T129S & 87 & 106 & 131 \\
\hline R146E & 33 & 42 & 98 \\
\hline Q152E & 52 & 106 & 113 \\
\hline MD & 100 & 100 & 100 \\
\hline M-IRS & 28 & 39 & 90 \\
\hline M-EE & 44 & 21 & 106 \\
\hline M-IRSEE & 7 & 5 & 40 \\
\hline $\mathrm{MD}$ & 100 & 100 & 100 \\
\hline F120A & 5 & 1 & 23 \\
\hline F120V & 13 & 12 & 71 \\
\hline F120I & 13 & 52 & 117 \\
\hline F120L & 22 & 70 & 113 \\
\hline F120Y & 67 & 97 & 190 \\
\hline F120W & 19 & 19 & 86 \\
\hline Il45A & 40 & 25 & 108 \\
\hline $\mathrm{I} 145 \mathrm{~F}$ & 94 & 220 & 202 \\
\hline F120A/I145A & 3 & 1 & 18 \\
\hline F120I/I145F & 18 & 39 & 83 \\
\hline $\mathrm{A} 144 \mathrm{~F}$ & 1 & 1 & 18 \\
\hline F120A/A144F & $<1$ & 1 & 16 \\
\hline E12 + EMSV & & N.A. ${ }^{a}$ & 24 \\
\hline $\mathrm{MD}+\mathrm{EMSV}$ & & N.A. ${ }^{a}$ & 23 \\
\hline EMSV & & 2 & 0.4 \\
\hline
\end{tabular}

To analyze the transcriptional activation of the MyoD mutants, the MyoD expression plasmids and the E-box-CAT reporter plasmid were transfected together with the control plasmid pEMSV into C3H10T1/2 mouse fibroblast cells. For the MDE12 coexpression experiments, the E12 expression plasmid was cotransfected instead of the pEMSV plasmid. The CAT activity was normalized to the amount of protein in the cultures and is shown relative to the activity of wild-type MyoD. The average values from the three experiments are shown, and the standard errors are from 5 to $15 \%$ of the average. Relative dimerization and DNA-binding activities $(\times 8 \mathrm{M} \Delta \mathrm{B} 2)$ are described in Figs. 2, 3 , and 4 .

${ }^{a}$ (N.A.) Not available.

ficity is determined, at least in part, by very few nonhydrophobic residues in the HLH domain.

\section{Construction of a MyoD analog with increased preference for homodimerization}

Based on these mutation results, we tried to construct a MyoD analog with a higher affinity for the formation of the homodimer that would contribute to a study of the MyoD homodimer function. We have identified $\mathrm{Arg}^{146}$ in MyoD helix 2 as one of the important residues for heterodimerization specificity (see Fig. 4). Using the parallel four-helix model of the bHLH domain dimer (Anthony et al. 1992; Halazonetis and Kandil 1992), we calculated that $\mathrm{Glu}^{584}$ in E12 helix 1 was close enough to $\mathrm{Arg}^{146}$ to allow effective electrostatic interactions. The attractive interaction was also suggested by the substitution of Arg ${ }^{146}$ with Glu, which lowered the dimerization affinity with E12 (see Fig. 4). This substitution presumably reverted the electrostatic charge at residue 146, therefore, it not only eliminated the attractive charge interaction between the pair of residues but also generated repulsive force. In the case of the MyoD homodimer, the pair of interacting residues are predicted to be $\operatorname{Arg}^{146}$ in helix 2 and $\mathrm{Thr}^{122}$ in helix 1, with the latter corresponding to Glu ${ }^{584}$ in E12. Therefore, if $\mathrm{Thr}^{122}$ is replaced with a negatively charged residue such as Glu, similar to the corresponding residue in E12, the mutant MyoD should form the homodimer with a higher affinity when compared with wild-type MyoD. As expected, T122E mutant MyoD bound DNA as the homodimer with higher affinity than the wild-type MyoD (Fig. 7). The T122E-E12 heterodimer bound DNA almost as well as the wild-type MyoD-E12 heterodimer with a slightly lower affinity, suggesting that the mutation did not increase dimerization affinity generally through some type of secondary effect. Substitution with Leu at the same position, T122I, did not have any effects on either heterodimerization (see Fig. 4) or homodimerization (data not shown/. We also tested M-IRSEE and Dmyd proteins as negative controls, which bound DNA with lower affinity as either E12 heterodimers or homodimers (Fig. 7).

\section{Discussion}

Based on numerous studies with DNA-binding proteins, it is clear that the sequence specificity of DNA binding can be demonstrated in competition experiments using either DNA fragments containing specific binding sites or their mutated derivatives. In contrast, the dimerization specificity of DNA binding proteins, such as the bHLH proteins (Voronova and Baltimore 1990; Braun and Arnold 1991; Sun and Baltimore 1991), has been studied in the absence of any specific competitor for dimerization. Here, we have established that the dimerization specificity of the myogenic bHLH factors can be shown experimentally in gel mobility-shift assays when a specific competitor protein is included in the reaction.

To understand the dimerization specificity of $\mathrm{MyoD}$ and $\mathrm{E} 12$, it was important to analyze the experimental results of various mutations presented above based on the protein structure of the bHLH domain. However, neither the fine structure of MyoD protein nor that of E12 protein has been determined. Recently, the crystal structure of the Max homodimer-DNA complex was reported (Ferré-D'Amaré et al. 1993). Max is a DNA-binding protein in a family of bHLHZip proteins (Blackwood and Eisenman 1991; Prendergast et al. 1991). Max forms a homodimer or a heterodimer with c-Myc to bind a similar E-box site. The HLH region of bHLHZip proteins 


\begin{tabular}{|c|c|c|c|c|c|c|c|c|c|c|c|}
\hline \multirow{5}{*}{$\begin{array}{l}\text { A } \\
\text { MyoD (MD) } \\
\text { Myogenin } \\
\text { Myf5 } \\
\text { MRF4 }\end{array}$} & \multirow{2}{*}{\multicolumn{3}{|c|}{ helix 1}} & \multicolumn{4}{|c|}{ helix? } & \multicolumn{4}{|l|}{$D$} \\
\hline & & & & loop & & $\times 2$ & & & \multicolumn{3}{|c|}{ dimerization/DNA binding (\%MD) } \\
\hline & VNE & ETL & $\mathrm{RC}$ & TSTNPNQRLPK & VE I LRNA & I RY & ESLQ & & \multicolumn{2}{|c|}{ E12 heterodimer } & \multirow{2}{*}{$\frac{\text { homodimer }}{\mathrm{M} \triangle \mathrm{B} 2(\mathrm{X} 3)}$} \\
\hline & $Q$ & A & & $\mathrm{TL}$ & & & & & - & $\mathrm{B} 2(\mathrm{X} 8)$ & \\
\hline & 1 & A & $\mathrm{R}$ & VA & $\mathrm{S}$ & $\mathrm{s}$ & $\mathrm{R}$ & & & & \\
\hline \multirow[t]{4}{*}{ Dmyd } & & 1 & $\mathrm{R}$ & S & & $E$ & $E$ & MyoD (MD) & 100 & 100 & 100 \\
\hline & & & & & & & & Myogenin & 90 & 65 & 66 \\
\hline & & 20 & & 130 & 140 & & 150 & Myf5 & 105 & 103 & 127 \\
\hline & & & & & & & & MRF4 & 90 & 30 & 27 \\
\hline
\end{tabular}

Figure 6. Dimerization and DNA binding of four myogenic bHLH factors. (A) Amino acid sequence comparison in the $\mathrm{HLH}$ region of the myogenic factors. Only amino acid changes that differ from MyoD (MD) (Lin et al. 1989) are shown for Myf5 (Braun et al. 1989), myogenin (Edmondson and Olson 1989; Wright et al. 1989), MRF4 (Rhodes and Konieczny 1989), and Dmyd (Paterson et al. 1991). The residue numbers for MyoD are indicated below. $(B)$ Heterodimerization and DNA binding of the four myogenic factors. Myogenic bHLH proteins ( $20 \mathrm{ng}$ ) were reacted with E12 $(60 \mathrm{ng})$ in the absence $(-)$ or the presence of an eightfold excess of $\mathrm{M} \Delta \mathrm{B} 2$ protein $[\mathrm{M} \Delta \mathrm{B} 2(\times 8)]$ in the gel shift reaction mixture. The positions of myogenic factor-E12 heterodimer-DNA complex (ME) and myogenic factor homodimer-DNA complex (MM) are indicated. MRF4 formed the E12 heterodimer-DNA complexes with two different mobilities in this study. (C) Homodimerization and DNA binding of the four myogenic factors. Myogenic bHLH proteins $(60 \mathrm{ng})$ were analyzed by the gel mobility shift as described in $B$ in the presence of threefold excess $\mathrm{M} \Delta \mathrm{B} 2[\mathrm{M} \Delta \mathrm{B} 2(\times 3)]$. The positions of complexes are indicated (MM). MRF4 also formed the homodimer complexes with two different mobilities. (D) Summary of dimerization of DNA binding of four myogenic factors. The numbers are represented as the average value of three similar experiments including one described in $B$ and $C$.

is significantly related to that of bHLH proteins in amino acid sequence (Murre et al. 1989). Therefore, it seemed reasonable, as a first approximation, to use the Max homodimer structure for the preliminary analysis of the MyoD-E12 heterodimer. Figure 8B shows the bHLH domain portion of the Max homodimer bound to DNA that was constructed by trimming out the Zip coiled-coil domains from the original structure (Ferré-D'Amaré et al. 1993). The amino acid sequences of MyoD and E12 were aligned to the Max sequence so that the Phe residue in helix 1 or the Ala residue in helix 2 had the same position (Fig. 8A). The MyoD and E12 sequences were then superimposed on the Max crystal structure (Fig. 8B). The results of the mutational experiments presented here are consistent with this model. The three residues in MyoD that we identified by experimentation, $\mathrm{Cys}^{126}, \mathrm{Arg}^{146}$, and $\mathrm{Gln}^{152}$, were all located on the surface of MyoD relatively close to residues on the surface of E12; therefore, these residues could be involved in the intermolecular interactions with E12 (Fig. 8B, solid circle). Thr ${ }^{122}$ was also located at a position close enough to interact with E12 helix 2. Thr ${ }^{129}$ was in the loop region, which was too far away to interact with E12. The surface residues in E12 and MyoD close enough to interact were E12
Glu $^{616}$ to MyoD Cys ${ }^{126}$, E12 $\mathrm{Met}^{588}$ to MyoD Gln ${ }^{152}$, and E12 Glu ${ }^{584}$ to MyoD $\operatorname{Arg}^{146}$, respectively.

This led us to question whether dimerization specificity is governed, in part, by relatively simple rules. In the leucine zipper proteins, which are another family of dimeric DNA-binding proteins, the dimerization is regulated by the charged residues at the e and $g$ positions (O'Shea et al. 1992a,b). An attractive pair of charged residues at particular positions stabilizes the dimer or a repulsive pair acts to destabilize the dimer $\left(\mathrm{O}^{\prime}\right.$ Shea et al. 1992b; Vinson et al. 1993). Our mutation experiments, when superimposed on the model, provide the simplest explanation for the results with the MyoD mutation R146E. $\mathrm{Glu}^{584}$ and $\mathrm{Arg}^{146}$ are oppositely charged residues, therefore, these two side chains have an attractive interaction. Apparently, the substitution of Glu for Arg eliminates the attractive interaction and further produces a repulsive force that results in the weak dimerization of MyoD R146E and E12. A strongly interacting pair of residues at this position was used to make the analog of MyoD with a greater preference for homodimerization. This mutant MyoD, T122E, had increased homodimerization activity as expected (Fig. 7). This result also supports the idea that MyoD $\operatorname{Arg}^{146}$ and 


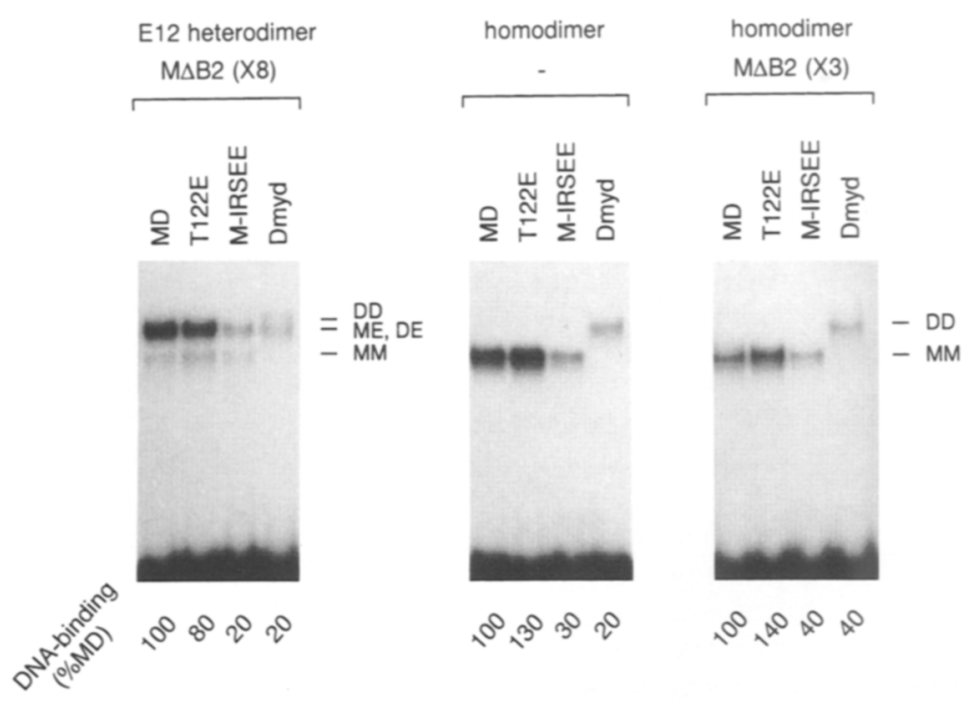

Figure 7. Higher affinity homodimer analog of MyoD. The heterodimerization with E12 or the homodimerization of the MyoD mutant T122E was analyzed by the gel mobility shift assay using the E-box sequence probe in the absence $(-)$ or the presence of $M \Delta B 2$ (eightfold excess or threefold excess). T122E (20 ng) and E12 (60 $\mathrm{ng}$ ) for the heterodimerization or T122E (60 ng) for the homodimerization were reacted. For the controls, the same amount of MyoD(MD) or M-IRSEE or Dmyd proteins was analyzed similarly. The positions of MyoD, T122E, and M-IRSEE homodimers (MM) and their heterodimers with E12 (ME), and Dmyd homodimer (DD) and Dmyd-E12 heterodimer (DE) are indicated. The DNA binding of MD was set as $100 \%$ in each panel.
E12 Glu ${ }^{584}$ form an attractive pair of residues that stabilize the MyoD-E12 dimer. We conclude that the charged pair rule can be applied at this particular site. Our results also demonstrate that an amino acid change at this position, even if it is a single change, can have significant effects on the dimerization specificity.

The results of mutation experiments also suggest that residues at the positions of $\mathrm{Cys}^{129}$ or $\mathrm{Gln}^{152}$ can form intermolecular pairs because C129R and Q152E substitutions change the charge at these residues and reduce the dimerization affinity by repulsive interactions. The residues nearest to these positions in the Max structure, Leu $^{613}$ and $\mathrm{Met}^{588}$, apparently do not form pairs of charged residues. Although it was not clear for Cys ${ }^{129}$ from the analysis of Max structure, we have found that $\mathrm{Glu}^{616}$ in E12 helix 2 is such a candidate residue for $\mathrm{Gln}^{152}$ of MyoD helix 2. Both are the last residues of helix 2 , which does not continue to the leucine zipper domain in the bHLH proteins; therefore, in theory, the locations of these two residues could be more flexible than allowed in the Max homodimer. Thus, the effects of the Q152E substitution could be explained by the forma-

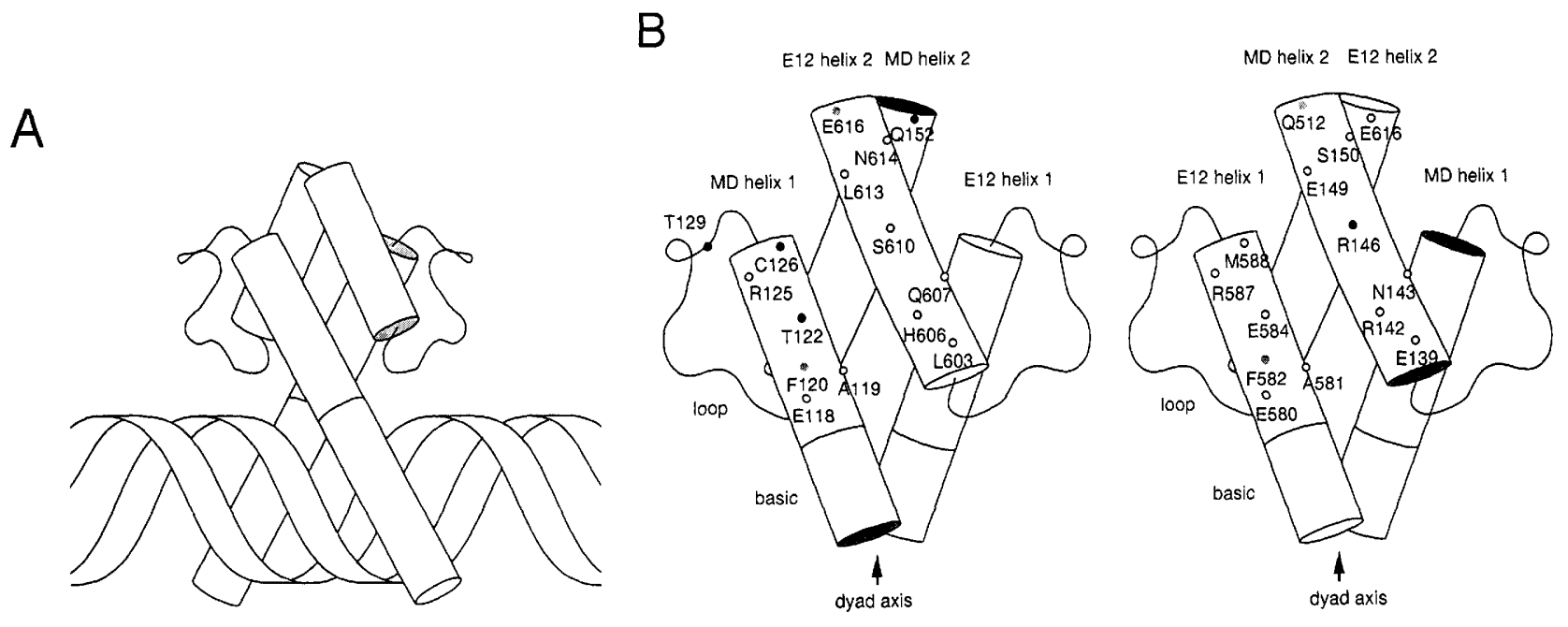

Figure 8. A bHLH dimer structure based on the Max homodimer coordinates. $(A)$ The schematic presentation of the bHLH domain structure in the Max (bHLHZip) homodimer bound to the B-form DNA. The $\alpha$-helix and the loop were shown by cylinders and lines, respectively. The region from residue 22 to 75 in the Max sequence is shown. Helix 2 is extended to the Zip domain and forms the coiled-coil structure in the original structure. $(B)$ The positions of MyoD or E12 amino acid residues superimposed onto the Max homodimer structure. The positions of $\mathrm{C}_{\alpha}$ (all circles) were plotted from the original image of the Max homodimer onto the schematic $\alpha$-helix or the loop. Only the residues located on the surface of the dimer are shown except Phe in helix 1 (MyoD Phe ${ }^{120}, \mathrm{E} 12 \mathrm{Phe}^{582}$ ) and the last residue of helix 2 (MyoD Gln ${ }^{152}, \mathrm{E} 12 \mathrm{Glu}^{616}$; shaded circles). The amino acids are identified by the single-letter code with the residue numbers in the original MyoD and E12 sequences. Five residues analyzed in the mutation experiments described in Figs. 2-4 are identified (solid circles). 
tion of a repulsive pair of Glu residues at this site. Further analysis of the Max crystal structure suggests two more attractive pairs between MyoD helix 2 and $\mathrm{E} 12$ helix 1: MyoD R142 and E12 E580, MyoD E149 and E12 R587 (Figs. 8 and 9). The distance between these pairs of residues was similar to the R146-E584 pair on the basis of the Max structure shown (Fig. 8), suggesting that the attractive interactions between these pairs of residues could stabilize the MyoD-E12 dimer. In summary, we propose that at least three intermolecular pairs of charged residues between MyoD helix 1 and E12 helix 2 and another pair between MyoD helix 2 and E12 helix 2 are involved in stabilizing or destabilizing the HLH dimer. Assuming that there is also dyad symmetry in the HLH dimer structure, at least seven residue pairs can be considered between the two HLH proteins that are potentially involved in dimer stabilization (Fig. 9).

We analyzed sequences at these seven positions to find attractive and repulsive pairs in homodimer or heterodimer combinations of several bHLH proteins. The numbers of each type of charged residue pairs, attractive or repulsive, and their net interactions were moderately correlated with the known DNA-binding activity of the bHLH dimers (Table 2). This suggests that the preliminary rules governing the dimerization specificity of the bHLH proteins will be based on the type of pairing scheme proposed here. The MyoD homodimer has the same number of attractive pairs as the MyoD-E12 heterodimer, but the heterodimer binds DNA with a higher affinity than the homodimer (Sun and Baltimore 1991). This suggests that the contribution of each pair may be unequal. Detailed mutational analysis of these residues should clarify further the rules of HLH interactions.

A similar analysis on the HLH domains of the bHLHZip proteins indicated the formation of very few attractive pairs (Table 2). This is consistent with the fact that the dimerization specificity of bHLHZip proteins, such as Myc, Max, TEFs, are regulated mainly by the Zip domains but not the HLH domains (Beckmann and $\mathrm{Ka}$ desch 1991; Amati et al. 1993). The Max structure model also confirms the importance of $\mathrm{Phe}^{120}$ in helix 1 in the structure of the hydrophobic interface that we also identified by mutation experiments (Fig. 5). Because most of the hydrophobic residues are conserved between the

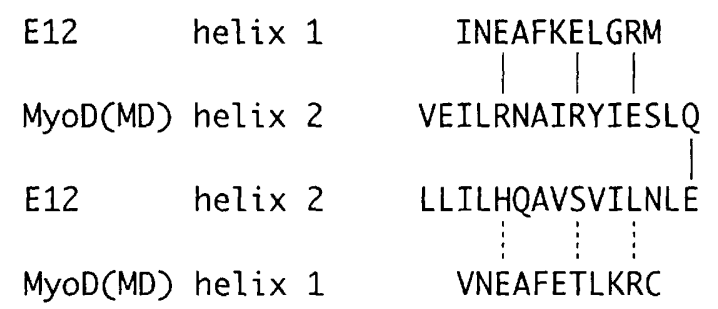

Figure 9. The residue pairs between the MyoD and E12 HLH domains. The pairs were suggested from the analysis of the Max homodimer structure. Four attractive pairs (solid vertical lines) and three nonattractive/nonrepulsive pairs (broken lines) in the MyoD-E12 heterodimer are indicated. Here, the Glu-Gln pair was considered as an attractive pair.
MyoD and Max HLH domains, MyoD Phe ${ }^{120}$ should have contacts with MyoD Lys ${ }^{137}$ in the loop (the starting residues of helix 2 in Max), MyoD Ilel40 in helix 2, and E12 Leu $^{605}$ in helix 2 based on the crystal structure (Ferré-D'Amaré et al. 1993). The substitution from Ala for Phe (F120A) apparently eliminates most of the contacts that form a hydrophobic core in the HLH dimer. Furthermore, the requirement of a Phe residue at this position for the bHLH proteins suggests that the two Phe side chains might interact with each other in the bHLH protein dimer. Although such contacts were not observed in the Max homodimer, the two side chains are at a relatively close distance $(5.1 \AA ; C \zeta-C \zeta)$ and theoretically might be close enough in the bHLH protein dimer where helix 2 is not under any constraints from the Zip coiled-coil domain.

The hydrophobic residues in the HLH domain are almost identical between MyoD (a bHLH protein) and Max (a bHLHZip protein) suggesting that these proteins have homologous hydrophobic interfaces (Blackwood and Eisenman 1991; Anthony et al. 1992). Despite the similarity, MyoD does not form a dimer with Max (Ayer et al. 1993). Our study suggests two reasons for this type of specificity. The sequence analysis of the hypothetical MyoD-Max dimer indicates that there are no attractive pairs formed at the seven positions identified above (Table 2). Thus, the dimer would not be stable enough even if the two proteins might appear to form the heterodimer. The mutational analysis at $\mathrm{MyoD} \mathrm{Phe}^{120}$ indicates that the Phe residue is indispensable for the dimerization of bHLH proteins (Fig. 5). However, several bHLHZip proteins, such as Mad (Blackwood and Eisenman 1991), USF (Gregor et al. 1990), CBF1 (Cai and Davis 1990), and TFEB (Fisher et al. 1991) have Ile instead of Phe, suggesting that the Phe is not indispensable for these factors. Furthermore, helix 2 apparently receives some constraint from the Zip coiled-coil domain with regard to its position in the bHLHZip dimer because the two domains form a continuous helix (Ferré-D'Amaré et al. 1993), whereas helix 2 in the HLH proteins apparently does not. This suggests that the hydrophobic interface of the HLH domains in the bHLH proteins and bHLHZip proteins may be slightly different and the stacking of hydrophobic residues may be insufficient to form the dimer between two types of HLH domains in the absence of additional stabilizing interactions such as the charged pairs discussed here.

The four myogenic regulatory factors, MyoD, myogenin, Myf5, and MRF4, can also convert fibroblasts to myoblasts and activate transcription through the E-box sites found in several muscle-specific genes (Davis et al. 1987; Tapscott et al. 1988; Braun et al. 1989; Edmondson and Olson 1989; Rhodes and Konieczny 1989; Wright et al. 1989; Brennan and Olson 1990; Weintraub et al. 1991). Although these factors show very similar functions in cultured cells, each of the factors is expressed with a distinct pattern during embryogenesis, suggesting that they have distinct functions in gene regulation during development (Montarras et al. 1991; Sassoon 1993). Consistent with this speculation, MyoD/Myf5, myoge- 
Table 2. The charged residue pairs in several dimers of bHLH and bHLHZip proteins

\begin{tabular}{|c|c|c|c|c|}
\hline & & \multicolumn{2}{|c|}{$\begin{array}{c}\text { Residue pairs } \\
\text { in HLH domain dimer }\end{array}$} & \multirow{2}{*}{$\begin{array}{l}\text { Dimerization/ } \\
\text { DNA binding }\end{array}$} \\
\hline & & attractive & repulsive & \\
\hline \multicolumn{5}{|l|}{ bHLH proteins } \\
\hline MyoD(MD) & E12 & 4 & 0 & + \\
\hline MyoD(MD) & MyoD(MD) & 4 & 0 & + \\
\hline E12 & E12 & 0 & 1 & - \\
\hline MyoD(MD) & $\mathrm{E} 47$ & 3 & 0 & + \\
\hline $\mathrm{E} 47$ & $\mathrm{E} 47$ & 4 & 1 & + \\
\hline Dmyd & E12 & 3 & 1 & $+1-$ \\
\hline Dmyd & Dmyd & 4 & 2 & $+1-$ \\
\hline \multicolumn{5}{|c|}{ bHLHZip proteins } \\
\hline Myc & $\operatorname{Max}$ & 1 & 1 & + \\
\hline $\operatorname{Max}$ & Mad & 2 & 0 & + \\
\hline Myc & Myc & 0 & 2 & $+1-$ \\
\hline Max & $\operatorname{Max}$ & 0 & 1 & + \\
\hline Mad & Mad & 0 & 1 & - \\
\hline \multicolumn{5}{|c|}{ bHLH-bHLHZip } \\
\hline MyoD(MD) & Myc & 2 & 1 & - \\
\hline MyoD(MD) & $\operatorname{Max}$ & 0 & 1 & - \\
\hline MyoD(MD) & Mad & 1 & 2 & - \\
\hline
\end{tabular}

The amino acid sequences of MyoD, E12, E47, Dmyd, Myc, Max, and Mad were aligned to find the charged residue pairs described in Fig. 9. Attractive pairs, Arg-Glu, Lys-Glu, Glu-Gln; Repulsive pairs, Arg-Arg, Lys-Lys, Glu-Glu. Only the total numbers are shown. The DNA binding was based on our results (Fig. 7) and the reports of others (Sun and Baltimore 1991; Blackwood and Eisenman 1991; Ayer et al. 1993).

nin, and MRF4 each show a different affinity for E12, suggesting a different specificity in dimerization among the four myogenic factors (Fig. 6). The E2A gene encodes three related proteins, E12, E47, and E2-5, that are translated from the alternatively spliced transcripts (Henthorn et al. 1990; Sun and Baltimore 1991). In addition, the E2A-related proteins, E2-2 (Henthorn et al. 1990) and HEB (Hu et al. 1992), are also expressed in the same cells but are encoded by distinct genes. All of these E2A gene products and related bHLH proteins can heterodimerize with the four myogenic factors (Braun and Arnold 1991; Hu et al. 1992). Our results suggest that the four myogenic factors would each have a different dimerization preference for the various E12-related proteins. Thus, gene regulation by the myogenic factors would not be modulated by their expression levels alone but also by the expression level of each E12-related partner protein. This would suggest specific dimerization of the myogenic factors; and ultimately, expression levels of the target gene are regulated by competition among the myogenic factors and the E12-related proteins. Transgenic mice lacking a functional MyoD or Myf5 gene still develop normal muscle (Braun et al. 1993; Rudnicki et al. 1993). Myogenic factors can convert fibroblast cells to myoblasts in which the E2A gene has been disrupted by gene targeting methods (Zhuang et al. 1992). These apparent functional compensations need to be considered in light of the results reported here: The differences in the dimerization specificity encoded in particular nonhydrophobic residues in the HLH domain may be revealed only under certain competitive conditions occur- ring among the bHLH proteins in cells. Compensatory bHLH proteins may be involved in maintaining the normal phenotype.

Further analytical studies, such as reports published for the Fos/Jun leucine zipper domain interaction (Kim and Little 1992; O'Shea et al. 1992b), reveal the dimerization and DNA-binding kinetics of the bHLH proteins described here. However, an implication of this work is that the use of a non-DNA-binding competitor protein in gel mobility-shift assays can facilitate the study of the specific dimerization of DNA-binding proteins in vitro. Under these conditions, it may be possible to identify the residues determining the dimerization specificity and elucidate some of the transcriptional regulation involving multiple regulatory DNA-binding proteins that have similar dimerization domains and target sequences.

\section{Materials and methods}

\section{Proteins}

To express His-tagged proteins in E. coli, complete coding regions for MyoD (CMD1) (Lin et al. 1989) and E12 (CE12) (Q. Wei, M. Shirataka, and B. Paterson, unpubl.) were subcloned into the pRSET plasmid (Invitrogen) and expressed in the BL21(pLysS) cells. The cells were collected from $300-\mathrm{ml}$ cultures and were suspended in $5 \mathrm{ml}$ of the extraction buffer containing $0.5 \mathrm{M} \mathrm{NaCl}, 50 \mathrm{mM}$ Tris $\mathrm{HCl}(\mathrm{pH} 7.5), 2 \mathrm{~mm}$ dithiothreitol, $10 \%$ (vol $/ \mathrm{vol}$ ) glycerol, $0.1 \%$ (vol/vol) NP- $40,0.2 \mathrm{~mm}$ phenylmethylsulfonyl fluoride, $0.5 \mu \mathrm{g} / \mathrm{ml}$ of E-64, $50 \mu \mathrm{g} / \mathrm{ml}$ of antipain dihydrochloride, and $0.7 \mu \mathrm{g} / \mathrm{ml}$ of pepstatin. The samples were sonicated for $5 \mathrm{~min}$ on ice and centrifuged for $1 \mathrm{hr}$ at 
25,000 rpm with the 50Ti rotor (Beckman). The His-tagged proteins were purified from the supernatant fractions by Ni-NTA agarose column chromatography (Hoffmann and Roeder 1991) and FPLC (Pharmacia-LKB). The purity of all the samples used was $90-95 \%$ based on the densitometry of SDS-polyacrylamide gels. To prepare other myogenic regulatory factors, cDNA clones for the complete coding region of the chicken homologs of myogenin, Myf5, MRF4 (B.M. Paterson and Q. Wei, unpubl.), as well as Dmyd (Paterson et al. 1991), were isolated. These factors and the MyoD mutants were prepared by similar methods described for MyoD.

\section{Gel mobility shift analysis}

The proteins used for gel mobility-shift experiments were all expressed in and purified from $E$. coli as described. For the probe DNA, the double-stranded and blunt-ended E-box DNA frag. ments were labeled by $\left[\alpha^{-32} \mathrm{P}\right] \mathrm{dCTP}$ (Amersham) with the Klenow enzyme. The E-box DNA sequence was 5'-AGCTTCCAACACCTGCTGCAAGCT- 3 ', derived from the mouse creatine kinase gene (Lassar et al. 1989). The bHLH proteins were premixed in the binding buffer $(10 \mu l)$ containing $0.15 \mathrm{M} \mathrm{KCl}, 25$ mM HEPES-KOH ( $\mathrm{pH} 7.9$ ), $2.5 \mathrm{~mm} \mathrm{MgCl} 2,20 \mathrm{~mm}$ dithiothreitol, $2.5 \%$ (vol/vol $)$ glycerol, $0.1 \%$ (vol/vol) NP- $40,50 \mathrm{ng} / \mu \mathrm{l}$ of bovine serum albumin (Boehringer). The probe DNA $\left(2 \times 10^{5}\right.$ $\mathrm{cpm})$ and poly[d(I-C)] $(1 \mu \mathrm{g})$ in the binding buffer containing 10 $\mu l$ were added to the protein mixture $(10 \mu l)$ without preincubation. The protein and probe DNA mixture $(20 \mu l)$ were incubated for $15 \mathrm{~min}$ at $37^{\circ} \mathrm{C}$. The samples were loaded on native polyacrylamide gels $[5 \%(\mathrm{wt} / \mathrm{vol})]$. The electrophoresis was carried out at $100 \mathrm{~V}$ for $1.5 \mathrm{hr}$ at room temperature using the electrophoresis buffer containing $106 \mathrm{~mm}$ Tris, $89 \mathrm{~mm}$ boric acid, and $0.1 \%$ (vol/vol) NP-40. Quantification of radioactivity in a gel was carried out with the Bio-Image Analyzer BAS2000 (FUII). Radiation dose is presented as PSL units that are proportional to dpm units, as described in the manufacturer's manual.

\section{Construction of MyoD mutant cDNAs}

To construct the chimeric MyoD, two restriction sites, BstEII and SphI, were created at the positions corresponding to the ends of the Cys-bHLH regions in CMD1 (Lin et al. 1989) and Dmyd (Paterson et al. 1991) cDNAs by site-directed mutagenesis (Bio-Rad). As a result of these mutations, $\mathrm{MD}^{\prime}, \mathrm{MdBHLH}$, $\mathrm{M} \triangle \mathrm{B}$, and $\mathrm{MdHLH}$ have the following amino acid substitutions: $\mathrm{Ala}^{81}-\mathrm{Gly}^{82}$ to $\mathrm{Gly}^{81}-\mathrm{Asp}^{82}$ at the BstEII site and $\mathrm{Ala}^{153}-\mathrm{Leu}^{154}$ to Gly ${ }^{153}-\mathrm{Met}^{154}$ at the ${ }^{\mathrm{Sph}} \mathrm{I}$ site. The effects caused by these mutations were not detectable in any of the experiments presented. Other mutant MyoD cDNAs were constructed by sitedirected mutagenesis in conjunction with PCR methods. The structures of all the mutants were confirmed by sequencing (U.S. Biochemical).

\section{Coimmunoprecipitation}

For in vitro transcription of MyoD and E12B RNA, the cDNAs were subcloned downstream of the $\mathrm{T} 3$ promoter in $\mathrm{pBS} \mid+1$ (Stratagene) and transcribed in vitro (Stratagene). The RNA was translated in vitro with the wheat germ extracts (Promega) and labeled with $\left[{ }^{35} \mathrm{~S}\right]$ methionine. The binding reaction and precipitation procedures were described previously (Davis et al. 1987).

\section{Cell culture and transfection}

Wild-type MyoD (MD) and the various mutant $\mathrm{MyoD}$ and wildtype E12 cDNAs were cloned into the expression plasmid
(pEMSV) (Harland and Weintraub 1985). The reporter plasmid contained the CAT gene transcribed from the thymidine kinase promoter (pBLCAT2) (Luckow and Schuts 1987). The same E-box sequence used for the gel mobility shift experiments was inserted $5^{\prime}$ to the promoter. The MyoD expression plasmids $(2.5$ $\mu \mathrm{g})$ and the E-box-CAT reporter plasmid $(2 \mu \mathrm{g})$ were transfected together with the control plasmid pEMSV $(2.5 \mu \mathrm{g})$ into C3H10T1/2 mouse fibroblast cell cultures (60-mm dish) using DOTAP (Boehringer). For the MD-E12 coexpression experiments, the E12 expression plasmid $(2.5 \mu \mathrm{g})$ was cotransfected instead of the pEMSV plasmid. The cells were maintained for 3 days in Dulbecco's modified Eagle medium (DMEM) containing $10 \%(\mathrm{vol} / \mathrm{vol})$ fetal bovine serum. The CAT activity in the cells was assayed with $\left[{ }^{14} \mathrm{C}\right]$ chloramphenicol and $n$-butylyl CoA (Promega).

\section{Max homodimer structure}

The coordinates of Max homodimer (Ferré-D'Amaré et al. 1993), which were kindly provided by Dr. S.F. Burley (Rockefeller University), were analyzed with the QUANTA (version 3.3.3). The schematic drawings (Fig. 8) were made from the ribbon graph created by the software. The positions of $\mathrm{C}_{\alpha}$ were copied directly on the drawings from the original image.

\section{Acknowledgments}

We thank Stephen F. Burley for the Max homodimer coordinates, Michael Lichten, Claude Klee, and Maxine Singer for critical reading of the manuscript, and Juanita Eldridge for the synthesis of oligonucleotides.

The publication costs of this article were defrayed in part by payment of page charges. This article must therefore be hereby marked "advertisement" in accordance with 18 USC section 1734 solely to indicate this fact.

\section{References}

Amati, B., M.W. Brooks, N. Levy, T.D. Littlwood, G.I. Evan, and H. Land. 1993. Oncogenic activity of the c-Myc protein requires dimerization with Max. Cell 72: 233-245.

Anthony, C.S., P.A. Benfield, R. Fairman, Z.R. Wasserman, S.L. Brenner, W. Stafford, C. Altenbach, W.L. Hubbell, and W.F. DeGrado. 1992. Molecular characterization of helix-loop-helix peptides. Science 255: 979-983.

Ayer, D.E., L. Kretzner, and R.N. Eisenman. 1993. Mad: A heterodimeric partner for Max that antagonizes Myc transcriptional activity. Cell 72: 211-222.

Beckmann, H. and T. Kadesch. 1991. The leucine zipper of TFE3 dictates helix-loop-helix dimerization specificity. Genes \& Dev. 5: 1057-1066.

Benezra, R., R.L. Davis, D. Lockshon, D.L. Turner, and H. Weintraub. 1990. The protein Id: A negative regulator of helixloop-helix DNA binding proteins. Cell 61: 49-59.

Biggs, J., E.V. Murphy, and M.A. Israel. 1992. A human Id-like helix-loop-helix protein expressed during early development. Proc. Natl. Acad. Sci. 89: 1512-1516.

Blackwell, T.K. and H. Weintraub. 1990. Differences and similarities in DNA-binding preferences of MyoD and E2A protein complexes revealed by binding site selection. Science 250: 1104-1110.

Blackwood, E.M. and R.N. Eisenman. 1991. Max: A helix-loophelix zipper protein that forms a sequence-specific DNAbinding complex with Myc. Science 251: 1211-1217.

Braun, T. and H.H. Arnold. 1991. The four human muscle reg- 
ulatory helix-loop-helix proteins Myf3-Myf6 exhibit similar hetero-dimerization and DNA binding properties. Nucleic Acids Res. 19: 5645-5651.

Braun, T., G. Buschhhausen-Denker, E. Bober, E. Tannich, and H.H. Arnold. 1989. A novel human muscle factor related to but distinct from MyoD1 induces myogenic conversion in 10T1/2 fibroblasts. EMBO J. 8: 701-709.

Braun, T., M.A. Rudnicki, H.-H. Arnold, and R. Jaenisch. 1993. Targeted inactivation of the muscle regulatory gene Myf-5 results in abnormal rib development and perinatal death. Cell 71: 369-382.

Brennan, T.J. and E.N. Olson. 1990. Myogenin resides in the nucleus and acquires high affinity for a conserved enhancer element on heterodimerization. Genes \& Dev. 4: 582-595.

Cai M. and R.W. Davis. 1990. Yeast centromere binding protein CBF1, of the helix-loop-helix protein family, is required for chromosome stability and methionine protrophy. Cell 61: $437-446$.

Chen, D. and K. Brew. 1989. Effects of modifying individual amino or carboxyl groups on the affinity of calmodulin for calcineurin. J. Biol. Chem. 264: 15367-15372.

Christy, B.A., L.K. Sanders, L.F. Lau, N.G. Copeland, N.A. Jenkins, and D. Nathans. 1991. An Id-related helix-loop-helix protein encoded by a growth factor-inducible gene. Proc. Natl. Acad. Sci. 88: 1815-1819.

Davis, R.L., H. Weintraub, and A.B. Lassar. 1987. Expression of a single transfected cDNA converts fibroblasts to myoblasts. Cell 51: 987-1000.

Davis, R.L., P.F. Cheng, A.B. Lassar, and H. Weintraub. 1990. The MyoD DNA binding domain contains a recognition code for muscle-specific gene activation. Cell 60: 733-746.

Edmondson D.G. and E.N. Olson. 1989. A gene with homology to the myc similarity region of $\mathrm{MyoDl}$ is expressed during myogenesis and is sufficient to activate the muscle differentiation program. Genes \& Dev. 3: 628-640.

Ellenberger, T.E., C.J. Brandl, K. Struhl, and S.C. Harrison. 1993. The GCN4 basic region leucine zipper binds DNA as a dimer of uninterrupted a helices: Crystal structure of the proteinDNA complex. Cell 71: 1223-1237.

Ferré-D'Amaré, A.R., G.C. Prendergast, E.B. Ziff, and S.K. Burley. 1993. Recognition by Max of its cognate DNA through a dimeric b/HLH/Z domain. Nature 363: 38-45.

Fisher D.E., C.S. Carr, L.A. Parent, and P.A. Sharp. 1991. TFEB has DNA-binding and oligomerization properties of a unique helix-loop-helix/leucine-zipper family. Genes \& Dev. 5: 2342-2352.

Gregor, P.D., M. Sawadogo, and R.G. Roeder. 1990. The adenovirus major late transcription factor USF is a member of the helix-loop-helix group of regulatory proteins and binds to DNA as a dimer. Genes \& Dev. 4: 1730-1740.

Halazonetis, T.D. and A.N. Kandil. 1992. Predicted structural similarities of the DNA binding domains of c-Myc and endonuclease EcoRI. Science 255: 464-466.

Harland, R. and H. Weintraub. 1985. Translation of mRNA injected into Xenopus oocytes is specifically inhibited by antisense RNA. J. Cell Biol. 101: 1094-1099.

Henthorn, P., M. Kiledjian, and T. Kadesch. 1990. Two distinct transcription factors that bind the immunoglobulin enhancer $\mu E 5 / \kappa 2$ motif. Science 247: 467-470.

Hoffmann, A. and R.G. Roeder. 1991. Purification of his-tagged proteins in non-denaturing conditions suggests a convenient method for protein interaction studies. Nucleic Acids Res. 19: 6337-6338.

Hu, J.-S., E.N. Olson, and R.E. Kingston. 1992. HEB, a helixloop-helix protein related to E2A and ITF2 that can modulate the DNA binding ability of myogenic regulatory factors.
Mol. Cell. Biol. 12: 1031-1042.

Jones, N. 1990. Transcriptional regulation: Two sides to an incestous relationship. Cell 61: 9-11.

Karin, M. 1990. Too many transcription factors: Positive and negative interactions. New Biol. 2: 126-131.

Kim, B. and J.W. Little. 1992. Dimerization of a specific DNAbinding protein on the DNA. Science 255: 203-206.

Landschulz, W.H., P.F. Johnson, and S.L. McKnight. 1989. The DNA binding domain of the rat liver nuclear protein C/EBP is biparticle. Science 243: 1681-1688.

Lassar, A.B., J.N. Buskin, D. Lockshon, R.L. Davis, S. Apone, S.D. Hauschka, and H. Weintraub. 1989. MyoD is a sequence-specific DNA binding protein requiring a region of myc homology to bind to the muscle creatine kinase enhancer. Cell 58: 823-831.

Lassar, A.B., R.L. Davis, W.E. Wright, T. Kadesch, C. Murre, A. Voronova, D. Baltimore, and H. Weintraub. 1991. Functional activity of myogenic HLH proteins requires hetero-oligomerization with E12/E47-like proteins in vivo. Cell 66: 305315.

Lin, Z.-Y., C.A. Dechesne, J. Eldridge, and B.M. Paterson. 1989. An avian muscle factor related to $\mathrm{MyoDl}$ activates musclespecific promoters in nonmuscle cells of different germ-layer origin and in BrdU-treated myoblasts. Genes \& Dev. 3: 986996.

Luckow, B. and G. Schuts. 1987. CAT constructions with multiple unique restriction sites for the functional analysis of eukaryotic promoters and regulatory elements. Nucleic Acids Res. 15: 5490.

Michelson, A.M., S.M. Abmayr, M. Bate, A.M. Arias, and T. Maniatis. 1990. Expression of a MyoD family member prefigures muscle pattern in Drosophila embryos. Genes \& Dev. 4: 2086-2097.

Montarras, D., J. Chelly, E. Bober, H. Arnold, M.O. Ott, F. Gros, and C. Pinset. 1991. Developmental patterns in the expression of Myf5, MyoD, myogenin, and MRF4 during myogenesis. New Biol. 3: 592-600.

Murre, C., P.S. McCaw, and D. Baltimore. 1989. A new DNA binding and dimerization motif in immunoglobulin enhancer binding, daughterless, MyoD, and myc proteins. Cell 56: $777-783$

O'Shea, E.K., J.D. Klemm, P.S. Kim, and T. Alber. 1992a. X-ray structure of the GCN4 leucine zipper, a two-stranded, parallel coiled coil. Science 254: 539-544.

O'Shea, E.K., R. Rutkowski, and P. Kim. 1992b. Mechanism of specificity in the Fos-Jun oncoprotein heterodimer. Cell 68: 699-708.

Paterson, B.M., U. Walldorf, J. Eldridge, A. Dubendorfer, M. Frasch, and W.J. Gehring. 1991. The Drosophila homologue of vertebrate myogenic-determination genes encodes a transiently expressed nuclear protein marking primary myogenic cells. Proc. Nat1. Acad. Sci. 88: 3782-3786.

Paterson, B.M., M. Shirakata, S. Nakamura, C. Dechesne, U. Walldorf, J. Eldridge, A. Dubendorf, M. Frasch, and W. Gehring. 1992. Isolation and functional comparison of Dmyd, the Drosophila homologue of the vertebrate myogenic determination genes, with CMDl. Proceeding of the British Society for Experimental Biology, pp. 89-109. London, UK.

Prendergast, G.C., D. Lawe, and E.B. Ziff. 1991. Association of Myn, the murine homolog of Max, with c-Myc stimulates methylation-sensitive DNA binding and ras cotransfection. Cell 65: 395-407.

Rhodes, S.J. and S.F. Konieczny. 1989. Identification of MRF4: A new member of the muscle regulatory factor gene family. Genes \& Dev. 3: 2050-2061. 
Rudnicki, M.A., T. Braun, S. Hinuma, and R. Jaenisch. 1993. Inactivation of $\mathrm{MyoD}$ in mice leads to up-regulation of the myogenic HLH gene Myf-5 and results in apparently normal muscle development. Cell 71: 383-390.

Sassoon, D. 1993. Myogenic regulatory factors: Dissecting their role and regulation during vertebrate embryogenesis. Dev. Biol. 156: 11-23.

Starovansnik, M.A., T.K. Blackwell, T.M. Laue, H. Weintraub, and R.E. Klevit. 1992. Folding topology of the disulfidebonded dimeric DNA binding domain of the myogenic determination factor MyoD. Biochemistry 31: 9891-9903.

Sun, X.H. and D. Baltimore. 1991. An inhibitory domain of E12 transcription factor prevents DNA binding in E12 homodimers but not in E12 heterodimers. Cell 64: 459-470.

Sun, X.H., N.G. Copeland, N.A. Jenkins, and D. Baltimore. 1991. Id proteins Id 1 and Id2 selectively inhibit DNA binding by one class of helix-loop-helix proteins. Mol. Cell. Biol. 11: 5603-5611.

Tapscott, S.J., R.L. Davis, M.J. Thayer, P.-F. Cheng, H. Weintraub, and A.B. Lassar. 1988. MyoDl: A nuclear phosphoprotein requiring a myc homology region to convert fibroblasts to myoblasts. Science 242: 405-411.

Vinson C.R., T. Hai, and S.M. Boyd. 1993. Dimerization specificity of the leucine zipper-containing bZIP motif on DNA binding: Prediction and rational design. Genes \& Dev. 7: 1047-1058.

Voronova, A. and D. Baltimore. 1990. Mutations that disrupt DNA binding and dimer formation in the E47 helix-loophelix protein map to distinct domains. Proc. Nat1. Acad. Sci. 87: 4722-4726.

Weintraub, H., V.J. Dwarki, I. Verma, R. Davis, S. Hollenberg, L. Snider, A. Lassar, and S.J. Tapscott. 1991. Muscle-specific transcriptional activation by MyoD. Genes \& Dev. 5: 13771386.

Winter, B., T. Braun, and H.-H. Arnold. 1992. Co-operativity of functional domains in the muscle-specific transcription factor Myf5. EMBO /. 11: 1843-1855.

Wright, W.E., D.A. Sassoon, and V.K. Lin. 1989. Myogenin, a factor regulating myogenesis, has a domain homologous to MyoD. Cell 56: 607-617.

Zhuang, Y., C.G. Kim, S. Bartelmez, P. Cheng, M. Groudine, and H. Weintraub. 1992. Helix-loop-helix transcription factors E12 and E47 are not essential for skeletal or cardiac myogenesis, erythropoiesis, chondogenesis, or neurogenesis. Proc. Nat1. Acad. Sci. 89: 12132-12136. 


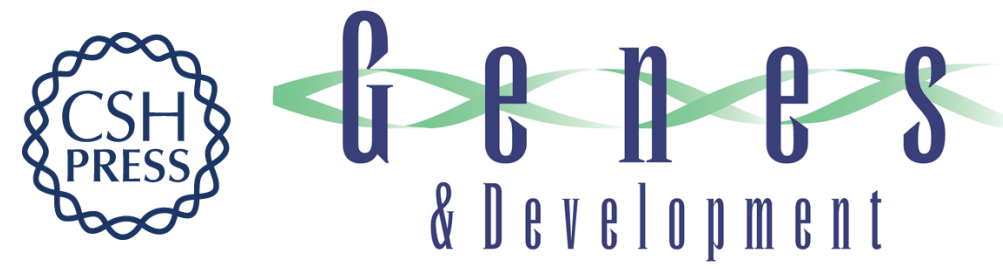

\section{Dimerization specificity of myogenic helix-loop-helix DNA-binding factors directed by nonconserved hydrophilic residues.}

M Shirakata, F K Friedman, Q Wei, et al.

Genes Dev. 1993, 7:

Access the most recent version at doi:10.1101/gad.7.12a.2456

References This article cites 55 articles, 27 of which can be accessed free at:

http://genesdev.cshlp.org/content/7/12a/2456.full.html\#ref-list-1

License

Email Alerting Receive free email alerts when new articles cite this article - sign up in the box at the top Service right corner of the article or click here.

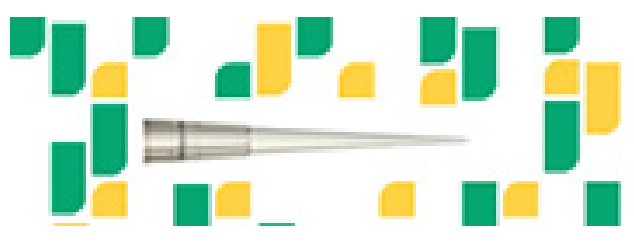

Focused on your science. 